\title{
CIDADES, POSSIBILIDADES E VIOLÊNCIAS: O RIO DE JANEIRO EM O SOL NA CABEÇA (2018)
}

Marcelo Reis ${ }^{1}$

\section{Introdução}

O Sol na Cabeça é uma coletânea de contos escritos por Geovani Martins, autor carioca nascido em Bangu, bairro da Zona Oeste da cidade. Por meio de sua obra, lançada em 2018, o escritor ilustra cenas típicas da juventude carioca, com experiências permeadas pela violência policial, a desigualdade social e o trânsito entre regiões próximas geograficamente, mas distantes na condução de suas interações. Pretende-se, por meio da articulação entre ficção, teoria e etnografia, compreender a presença de conceitos, campos de pesquisa e representações advindas das Ciências Sociais na obra de Martins. Faz-se também um esforço para captar como uma obra ficcional pode contribuir para os estudos urbanos, permitindo uma interlocução com grupos, espaços e sociabilidades.

A partir do livro, busca-se apreender rotinas, interações e moralidades presentes no recorte da realidade carioca apresentado por Geovani Martins. Os treze contos não serão abordados individualmente, em secções dedicadas a cada uma das estórias, já que o foco do trabalho está em suas similaridades e contrastes. Ao longo do texto, será devidamente apontado a qual conto se faz referência, tendo a cautela de inserir o leitor no universo da obra de Martins. O livro, portanto, passará por uma decupagem de modo a facilitar sua compreensão dentro do universo desta pesquisa, buscando agrupar categorias, cenários e conjunturas conforme suas aparições.

Passa-se a um diálogo com uma bibliografia, principalmente, da Antropologia Urbana. Na articulação entre teoria e ficção, há um destaque para conceitos como região moral (Park), pedaço (Magnani) e reserva (Simmel). Também se recorre ao debate sobre medo e violência desenvolvido por Caldeira (2011) e sobre o estabelecimento da sociedade complexa em Velho (2013).

Em referência a O'Donnell (2007: 137) e seu trabalho sobre o escritor João do Rio, essa pesquisa pretende demonstrar "práticas simbióticas entre espaço citadino e

\footnotetext{
${ }^{1}$ Instituto de Estudos Sociais e Políticos (IESP/UERJ), Brasil. E-mail: marcelofilho@iesp.uerj.br, ORCID: https://orcid.org/0000-0001-6183-1324
} 
violência cotidiana" por meio da literatura de Martins. Isso significa entender, de certo modo, os efeitos do cenário urbano, assim como de suas peculiaridades, na formação de moralidades, interações interpessoais, relações com o espaço e ações individuais. Nesse sentido, o presente trabalho é uma reflexão sobre a sociabilidade no Rio de Janeiro, utilizando os contos da obra selecionada como um objeto que ilustra, auxilia e constrói cenários para análise. É, portanto, uma tentativa de analisar as ruas cariocas por meio de uma obra da literatura contemporânea.

\section{A construção literária da cidade}

O Sol na Cabeça apresenta um Rio de Janeiro com diversas fronteiras e subjetividades. A obra de Martins nos leva a situações e cenários particulares de cada região da cidade. Gávea e Rocinha figuram entre os bairros da Zona Sul, enquanto a Zona Oeste é apresentada por meio da Barra da Tijuca, Bangu e Padre Miguel e a Zona Norte é representada por Jacaré e Jacarezinho. O Centro é o único bairro da zona central da cidade a aparecer nas estórias. Extrapolando os limites municipais, Arraial do Cabo, cidade da Região dos Lagos, é designada enquanto destino turístico em um dos contos.

Em um primeiro momento, este artigo dedica-se a compreender a articulação do medo e da violência na construção desse cenário. De acordo com Caldeira (2011: 27), "a fala do crime alimenta um círculo em que o medo é trabalhado e reproduzido, e no qual a violência é a um só tempo combatida e ampliada". Nesse sentido, aponta-se como o crime organiza, por meio das narrativas, as experiências e sentidos agenciados em torno do espaço urbano.

Isso significa, por exemplo, a formulação de políticas públicas de segurança de modo a mitigar a violência. Ao mesmo tempo, o setor privado oferece, por meio de empreendimentos imobiliários residenciais e comerciais, uma perspectiva de cuidado e afastamento desse espaço público supostamente violento. Assim, nota-se como a construção do medo e da violência influencia o trânsito e a ocupação de diferentes localidades, da mesma forma que desincentiva determinados modos de circulação e ocupação.

Quando a UPP invadiu o morro, era foda pra comprar bagulho. Maior escaldação; ninguém queria botar a cara pra vender, só tinha criança trabalhando de vapor. Uns moleque de oito, nove anos. Tinha vez que sentia até pena de ver as criança naquela situação, mas o papo é que a gente se 
acostuma com cada bagulho sinistro, que pena é coisa que dá e passa rápido; geral continuou comprando droga. (Martins, 2018: 24)

No trecho acima, presente no conto A história do Periquito e do Macaco, retratase a implementação de uma Unidade de Polícia Pacificadora (UPP) na Rocinha, localizada na Zona Sul carioca. O aparato policial era uma resposta ao domínio de traficantes em partes do território da cidade, visando uma ocupação do espaço pela Polícia Militar (PM). De acordo com dados do Instituto de Segurança Pública, foram criadas 38 UPPs entre 2008 e 2014.

A Polícia Militar ocupou a Rocinha em dezembro de 2011 e a instalação da Unidade teve conclusão em setembro do ano seguinte. Na obra de Martins (2018: 24), a instalação criou um cenário de "polícia sufocando, invadindo casa, esculachando morador por qualquer bagulho". O livro aponta que os abusos policiais não faziam parte da narrativa da imprensa, que apoiava o projeto de ocupação das comunidades.

Nesse sentido, diz-se que "as narrativas de crime elaboram preconceito e tentam eliminar ambiguidades" (Caldeira, 2008:28). As narrativas proporcionam um significado simbólico ao crime, reorganizando a realidade e as práticas criminosas em torno de um quadro de segregação nos espaços, discursos e costumes. A ocupação de uma favela, por exemplo, pode se inserir na narrativa de pacificação de uma cidade que passa por conflitos armados, proporcionando um lugar simbólico tanto para as UPPs quanto para o crime organizado.

As ambiguidades podem passar por uma tentativa de apagamento ao veicular-se o combate ao crime apenas pelo discurso oficial das forças de segurança. Elimina-se, dessa forma, as práticas de violência policial nas comunidades cariocas em meio a um plano de pacificação. Em outro sentido, mascara-se também as desigualdades e conflitos da vida urbana. Martins, por outro lado, ressalta as pluralidades do meio em que vive:

As pessoas costumam dizer que morar numa favela de Zona Sul é privilégio, se compararmos a outras favelas na Zona Norte, Oeste, Baixada. De certa forma, entendo esse pensamento, acredito que tenha sentido. O que pouco se fala é que, diferente das outras favelas, o abismo que marca a fronteira entre o morro e o asfalto na Zona Sul é muito mais profundo. É foda sair do beco, dividindo com canos e mais canos o espaço da escada, atravessar as valas abertas, encarar os olhares dos ratos, desviar a cabeça dos fios de energia elétrica, ver seus amigos de infância portando armas de guerra, pra depois de quinze minutos estar de frente pra um condomínio, com plantas ornamentais enfeitando o caminho das grades, e então assistir adolescentes fazendo aulas particulares de tênis. É tudo muito próximo e muito distante. E, quanto mais crescemos, maiores se tornam os muros. (Martins, 2018: 11). 
O relato do narrador de Espiral aponta para a construção de um cotidiano na Zona Sul carioca. O personagem insere-se enquanto morador de uma favela em uma região rica da cidade. A sua rotina, dessa forma, passa pelo convívio com o abismo de infraestrutura, renda, segurança e acesso a serviços entre o seu local de moradia e o bairro em que circula para frequentar sua escola.

Devido ao seu percurso, o personagem começa a perceber a reação de estudantes de escolas particulares e moradores diante da sua presença no bairro. A estória mostra o medo que homens e mulheres sentiam diante da circulação de um jovem de favela em seus espaços. $\mathrm{O}$ encontro entre o protagonista e seus interlocutores pode apontar uma narrativa do crime que marginaliza o narrador e, em outro sentido, também demonstra as tensões ao se transitar entre diferentes partes da cidade.

É, nesse sentido, que o protagonista se engaja no que descreve como uma "forma de pesquisa, estudo sobre relações humanas. Passei então a ser tanto cobaia quanto realizador de uma experiência." (Martins, 2018:12). O narrador escolhe um homem para seguir e assim faz durante três meses. Sem ser notado, descobriu o nome de seu escolhido, Mário, a residência e o local de trabalho.

No último momento da "experiência”, Mário é acompanhado até o prédio em que reside e, após chegar em seu apartamento, aparece na janela com uma pistola automática. O narrador sorri para o homem e percebe que para "continuar jogando esse jogo, precisaria também de uma arma de fogo" (Martins, 2018:14). Há, nesse sentido, o término do conflito entre as personagens diante da ameaça armada, constituindo ali um limite no espaço que o narrador não poderia ultrapassar.

Espiral pode ser compreendida como uma investigação sobre interações no meio urbano. O narrador, jovem proveniente de favela, e Mário, morador de bairro da Zona Sul, representam diferentes vertentes da mesma cidade. $\mathrm{O}$ encontro entre ambos mostra, de forma individualizada, o tensionamento entre esses espaços urbanos, dada a formulação de narrativas que marginalizam favelas e seus habitantes, ao mesmo tempo que valorizam e enclausuram bairros de maior poder aquisitivo. 
Figura 1 - Mapa da cidade do Rio de Janeiro com os bairros encenados no livro em cor vermelha

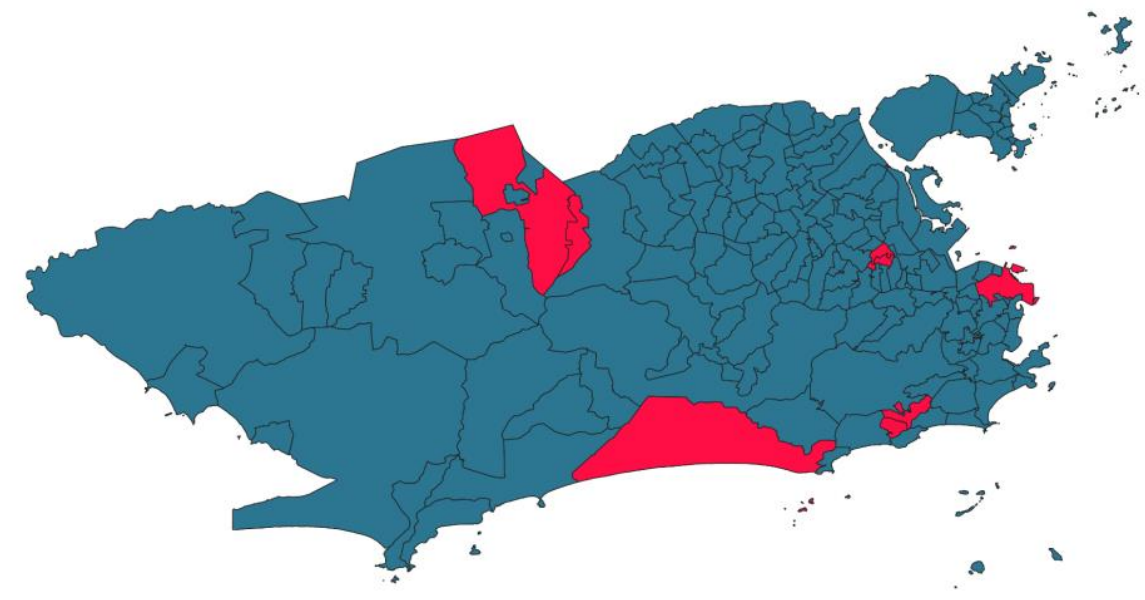

Fonte: Arquivo Pessoal

No mapa acima, a cor vermelha destaca os bairros que servem de palco para as tramas feitas por Martins ao longo do livro. Os vizinhos Bangu e Padre Miguel, na parte superior do mapa, aparecem em Primeiro Dia e Estação Padre Miguel. A Barra da Tijuca é cenário de Sextou, assim como Jacaré, Jacarezinho e Centro. As perseguições de Espiral levam o leitor ao bairro da Gávea. A História do Periquito e do Macaco tem a Rocinha como seu cenário.

A presença do Rio de Janeiro no imaginário do livro não se limita aos bairros em que os contos são encenados. Vidigal e São Conrado, ambos bairros da Zona Sul, Vila Vintém, favela da Zona Oeste, a Estrada da Gávea e diversas estações de trem, como São Cristóvão e Triagem, são espaços mencionados por narradores e personagens. A construção da cidade na obra se estende, portanto, aos locais presentes nas memórias e nos diálogos das personagens.

Nesse momento do artigo, pretende-se compreender como esses locais, mencionados e encenados, demonstram uma determinada circulação pela cidade e a construção de rotinas. Certeau (1998) aponta para o papel do sujeito no processo de reapropriação das estruturas urbanas. Assim, lança-se um olhar sobre os escapes da regulação e padronização do cotidiano.

A circulação das personagens, condensada na Figura 1, demonstra um circuito formulado a partir de atividades de trabalho, lazer, estudo e residências. A utilização 
dessas categorias não significa, por outro lado, que todas as cenas narradas se encaixam em uma narrativa de ordenação das rotinas. Em Sextou, destaca-se o seguinte encontro:

\begin{abstract}
Quando cheguei na porta da estação é que entendi o que a mulher tentou falar comigo: "Cuidado com os canas!". O PM apontou a pistola pra minha cara. Não foi a primeira e nem seria a última vez que alguém apontava pra mim uma arma. [...] Tinha só um casaco, um livro e, dentro dele, cem reais, o resto do meu pagamento.Os olhos do verme brilharam quando viu a grana, no entanto fingiu seriedade, entregando na minha mão e mandando segurar o meu dinheiro. [...] Nessa hora percebi que nenhum deles usava a identificação na farda, fiquei bolado deles forjarem um flagrante pra mim e me fazerem assinar o 12. Além do mais, ninguém podia me garantir que saindo dali eu ia parar na delegacia. Podiam muito bem sumir comigo e ficar com a grana. Sabia que ia perder, mas não conseguia acreditar. Passei a semana inteira pensando naquele dinheiro, planejando o que faria com ele, era como se fôssemos amigos. (Martins, 2018: 70 -71)
\end{abstract}

O narrador desse conto se desloca ao Jacarezinho, visando adquirir maconha, e, em seu caminho até a estação de trem, é surpreendido pela presença de policiais militares - que pegam seu dinheiro e o deixam levar a erva. Em seu dia-a-dia, o protagonista relata momentos de trabalho na Barra da Tijuca e no Centro, nos papéis de boleiro em uma quadra de tênis e entregador de papel, além de interações com sua mãe e padrasto em casa. A personagem, contudo, não se submete somente a momentos ordinários em sua trajetória e daí surgem os conflitos em sua rotina.

Nesse sentido, Sextou permite "compreender a dimensão profundamente conflitante da vida urbana contemporânea e os distintos mecanismos que subsidiam as práticas sociais que alteram a vida cotidiana" (Leite, 2010: 737-738). O narrador insere o leitor em um contexto de subversão da rotina de trabalho, escola e residência. O lazer, nesse caso representado pela compra e uso da maconha, entra em colisão com a normatividade em pelo menos dois momentos: o calote na passagem de trem e a negociação com os policiais pela posse do dinheiro e da droga.

Há, nessas situações, impasses aos objetivos do narrador. No caso da passagem, observa-se como o preço do transporte público se torna um obstáculo ao retorno para sua residência. Contorna-se isso ao utilizar uma entrada irregular ao lado da estação de trem.

Por outro lado, a negociação com os policiais militares demonstra uma ação policial irregular e modos de superá-la. O protagonista, ameaçado pelas armas dos policiais e acuado pela posse de droga em seus bolsos, dialoga com os PMs para conseguir manter seu dinheiro ou a maconha. Ao fim, ele perde cem reais enquanto "desenrolo", ou seja, pagamento para não ser levado para a delegacia e mantém a droga recém-adquirida. 
Mostra-se, nesse sentido, “a astúcia no relacionamento" (Certeau, 1998: 52) com o sistema policial vigente, com a personagem escapando dos possíveis enquadramentos jurídicos e do risco à sua vida que a situação apresentava.

Constrói-se, nesse sentido, um olhar sobre rotinas não-normativas. A obra de Martins permite observar como indivíduos escapam da padronização do cotidiano em estruturas urbanas, assim inventando novas maneiras de circular e interagir pela cidade. Além disso, demonstra-se a relação do medo e da violência nesses trânsitos urbanos, com essas categorias interagindo na formulação de interações e conflitos nas rotinas.

\section{Trajetórias e redes sob o Sol}

O conto Roleta-russa tem Paulo como narrador e protagonista. Almir, seu pai, o deixa sozinho na vila em que moram enquanto vai trabalhar. Devido ao seu emprego de segurança, há um revólver guardado em sua gaveta. Nesse cenário, narra-se encontros e jogos entre Paulo e outras crianças:

Fazia tempo que o polícia e ladrão não fluía tanto. A febre do momento era jogar à vera. Mata-mata, búlica, triângulo, figurinha, tazo no bafo. O importante era valer alguma coisa. Por essa razão, as brincadeiras de correr, as preferidas de Paulo, iam ficando pra trás. Exceto nos dias de festa de aniversário na rua, porque, nesses dias, todo mundo fica com vontade de correr e brincam de todos os piques do mundo. Controlando as brincadeiras durante a tarde, Paulo sentiu que era isso mesmo a vida, uma festa. (Martins, 2018: 18).

A perspectiva do lazer perto da residência de Paulo e Almir aponta para a existência de uma rede de sociabilidade no lugar em que moram. As interações com seus vizinhos e com os espaços próximos a si relembram a categoria pedaço, que pode ser definida como "ponto de referência para distinguir determinado grupo de freqüentadores como pertencentes a uma rede de relações" (Magnani, 2002: 21). Nesse sentido, a vila descrita no conto constitui um espaço físico e social em que se desenvolvem relações de pertencimento, amizades e atividades de lazer.

A relação de Paulo com seus colegas indica a repetição de encontros, jogos e brincadeiras. Há, nesse sentido, a criação do espaço intermediário entre as ruas e as casas ali presentes, constituindo o pedaço em que convivem. Em outro caso descrito pelo narrador, demonstra-se a "peculiar rede de relações" (Magnani, 2002: 21) pela aglomeração em torno de uma revista pornô descoberta na casa de uma das crianças. 
Quando chegou na rua, estavam todos amontoados em roda, se escalando. Ignoravam o sol na cabeça e, em vez de disputarem a pouca sombra que fazia o pé de acerola, brigavam pela melhor posição pra ver a fotonovela pornô que o Mingau achou em casa, revirando as coisas do primo desaparecido. Paulo se juntou à turma, sem muito interesse na revista. (Martins, 2018: 15).

Em outro sentido, os contos de Martins também relembram a sociabilidade urbana desenvolvida por Simmel (2005). O meio urbano, com sua economia monetária e intensa carga de estímulos nervosos, influencia os indivíduos a adotarem uma postura intelectualizada e dessensibilizada em relação a situações e pessoas ao seu redor. Assim, em grandes centros urbanos, é observável a reserva nas interações interpessoais e o caráter blasé diante dos acontecimentos.

A figura do entregador do papel em Sextou ilustra a teoria de Simmel. No relato do narrador, diz-se que "fazia o contato visual, me preparava pra entregar o papel; nessas horas, de alguma forma, sentia que aquelas pessoas preferiam que eu não existisse. $\mathrm{O}$ problema é que eu levava os olhares pro lado pessoal." (Martins, 2018: 66). Demonstrase, assim, o afastamento dos transeuntes do trabalhador que tentava se engajar em contato visual e, dessa forma, entregar o papel em suas mãos. Essa forma de ignorar - ou até mesmo desprezar - o entregador pode ser interpretada como uma técnica para evitar um contato com um desconhecido na cidade.

É importante notar que o narrador considera o afastamento um aspecto positivo no trabalho de entregador de papel. "Uma coisa boa desse trabalho é que não preciso falar com ninguém, tenho tempo pra ficar pensando, planejando minhas coisas, imaginando o futuro." (Martins, 2018: 65), diz a personagem. Percebe-se, por meio dessa fala, que o próprio entregador entende esse cenário como uma possibilidade para pensar em questões pessoais, evitando desgastar-se em interações com outros ali presentes.

Continuando no campo da sociabilidade urbana, percebe-se como os contos demonstram a heterogeneidade cultural e as classes sociais distinguíveis típicas de uma sociedade complexa, como apontado por Velho (2013). Em Espiral, o narrador descreve as pessoas que encontra na rua como de "mundo que não conheço" (Martins, 2018: 1213). Assim, aponta-se para distância entre o seu contexto, na favela em que morava, e dos moradores do "asfalto" da Zona Sul carioca.

As diferenças percebidas pela personagem também apresentam a noção de estigma. $\mathrm{O}$ narrador relata o receio que estudantes de colégios particulares sentiam ao ver ele e seus colegas se aproximando. Essa atitude, em um primeiro momento, era inesperada para ele, já que, em sua própria escola, "não metíamos medo em ninguém” (Martins, 
2018: 11). Observa-se que o narrador não atribuía a si ou a seus colegas uma característica depreciativa, mas passa ao notar que outros transeuntes lhe atribuem esse fator ao longo da estória. Portanto, relembra-se:

\begin{abstract}
O termo estigma, portanto, será usado em referência a um atributo profundamente depreciativo, mas o que é preciso, na realidade, é uma linguagem de relações e não de atributos. Um atributo que estigmatiza alguém pode confirmar a normalidade de outrem, portanto ele não é, em si mesmo, nem horroroso nem desonroso. [...] O termo estigma e seus sinônimos ocultam uma dupla perspectiva: Assume o estigmatizado que a sua característica distintiva já é conhecida ou é imediatamente evidente ou então que ela não é nem conhecida pelos presentes e nem imediatamente perceptível por eles? No primeiro caso, está-se lidando com a condição do desacreditado, no segundo com a do desacreditável. (Goffman, 2004: 6-7).
\end{abstract}

Em um primeiro momento, apontou-se a perspectiva do medo e da violência nas perseguições feitas em Espiral. Adiciona-se, então, como o narrador explora o estigma que lhe atribuem ao buscar entender as reações de outras pessoas que circulam pelo bairro. Nesse sentido, compreende-se como a classe social ou raça, não explicitada no conto, interage a outros fatores na produção de interações interpessoais durante os trânsitos cotidianos.

Além disso, a personagem explora as condições de desacreditado e desacreditável em seus percursos. O narrador compreende, em dados momentos, que outros lhe vêem enquanto ameaça, como no caso da idosa que estava próxima a um ponto de ônibus e se afastou quando ele se aproximou. Por outro lado, a experiência com Mário explorou até qual momento ele não seria percebido pelo seu alvo, então escondendo o fator depreciativo atribuído a si. Após três meses, o cenário mudou, já que Mário começou a perceber sua presença e evitar encontros com o narrador.

Em outro plano, os contos oferecem diversos casos de região moral (Park, 1979) em suas narrativas. Essas regiões são definidas por forma de expressão, representação e hábitos daqueles que por ela circulam ou a habitam. Isso significa um local que, por consequência, é influenciado e assume características dos grupos que se apropriam dele.

Da cracolândia só restava o lixo e o cheiro: copos de Guaravita, pedaços de roupas, filtros de cigarro, merda humana, isqueiros sem gás. Sentamos em cima dos trilhos, onde era sempre mais limpo do que as encostas do muro que cerca toda a linha do trem até chegar na estação. A noite tinha acabado de cair, e quando o consumo era liberado era esse o horário de pico. Juntava gente que saía do trabalho, da escola, os que desciam do trem e os que acampavam pela favela. A noite protegia os que tinham medo de explanar o vício. Quando escurecia, na linha do trem ninguém tinha mais nome nem 
rosto pra quem passasse de fora, era tudo um único monte de viciado. (Martins, 2018: 48).

No trecho acima, presente em Estação Padre Miguel, descreve-se o cenário da estação de trem que dá nome ao conto quando era conhecida como "cracolândia". O espaço, então, era apropriado por usuários e vendedores de crack, que se reuniam ali para venda e consumo da droga. Assim, notam-se elementos como os copos de Guaravita e isqueiros, utilizados para para fumar a pedra de crack.

Por meio dessa ocupação, o narrador relata que o espaço era reconhecido pelo hábito do consumo de crack. Contudo, o local perde essa característica quando traficantes pró́bem o uso dessa droga na região. Dessa forma, desarticulou-se a moralidade que prevalecia na estação, dado que os indivíduos que circulavam ali por esse motivo tiveram que se retirar.

A "cracolândia" descrita, em conjunto com a Vila Vintém, constituía uma mancha (Magnani, 2002) na região. A estação de trem tornou-se um ponto de referência para o consumo, venda e circulação entre aqueles que praticavam uso e venda de crack. $\mathrm{O}$ fornecimento da droga pelos traficantes da Vintém, com o ponto de encontro na estação próxima à favela, aglutinou os interessados na droga em torno de um espaço em comum.

Nesse sentido, compreende-se a formulação de trajetórias e redes na obra de Martins. Além disso, observa-se como a sociabilidade urbana é atravessada por diversas categorias que se articulam na produção da realidade social. Os contos apontam algumas dessas articulações, com o estigma, a formação de redes a partir do lazer e a representação moral no espaço físico.

\section{Conclusão}

O presente trabalho se debruçou sobre a sociabilidade na cidade do Rio de Janeiro, tendo como objeto o livro O Sol na Cabeça. Geovani Martins, por meio de seus contos, recria cenários e contextos da contemporaneidade carioca. Em suas narrativas, observase a interação de diversos elementos, tais como: preconceito de raça; preconceito de classe; violência policial; tráfico de drogas; lazer em vizinhanças; medo na experiência urbana; apropriações do espaço urbano e escapes da padronização do cotidiano.

Os contos apontam que "a cidade está enraizada nos hábitos e costumes das pessoas que a habitam. A consequência é que a cidade possui uma organização moral bem 
como uma organização física" (Park, 1979: 27-28). Isso significa uma compreensão da interação entre espaço e moral na formulação do que se entende como meio urbano. No caso observado, nota-se, por exemplo, a formulação da "cracolândia" em Padre Miguel, o pedaço em Roleta-russa e a narrativa do crime enquanto influência em $A$ história do Periquito e do Macaco.

Nesse sentido, relembrando O’Donnell (2007), pode-se dizer que a literatura de Martins incorporou as tensões da cidade do Rio de Janeiro. Nos contos analisados, os padrões sociais estão expostos e dissecados pelos narradores e personagens. As interações, a circulação pela cidade e os conflitos da vida urbana são representados ficcionalmente nas páginas analisadas, demonstrando por um olhar artístico os fenômenos tipicamente analisados pelas Ciências Sociais.

Destaca-se o estigma explorado pela personagem de Espiral. O narrador recria a transição entre favela e "asfalto" por meio de suas palavras, demonstrando o preconceito que pairava sobre si e sua curiosidade em explorar os limites daquela situação. A partir dessa ficção, pode-se entender a experiência da juventude carioca nesses momentos de tensão e conflito, assim como a percepção daqueles que são estigmatizados.

\footnotetext{
Para mim, não faz sentido falar em centro e em periferia - explica o autor, no caminho entre Vidigal e Bangu. - Por exemplo, quando a gente chegar a Bangu, quem vai ser periferia e quem vai ser centro? Tá ligado? A situação forma o que é uma coisa e o que é outra. E hoje a favela já é centro, ela tem autonomia, ela gira em torno dela própria, consome e cria cultura. Ali é a minha vida, como você vai dizer que é periferia? (Torres, 2018).
}

Por fim, nota-se essa fala do autor, em matéria do jornal $O$ Globo, no contexto do lançamento de seu livro. Martins propõe, então, uma revisão da própria noção de centralidade na cidade. Dialoga-se, portanto, com a ideia de produção do espaço urbano pelos seus próprios habitantes e das possibilidades de análise a partir dessa perspectiva. Compreender a centralidade exercida por diversos espaços, assim como as relações entre o espaço e o social apontadas por Magnani (2002), é observar os padrões sociais nãonormativos em toda sua complexidade.

A partir do debate proposto neste artigo, espera-se lançar um olhar sobre a capacidade de obras ficcionais de articular e demonstrar os padrões sociais. Os contos de Martins desenham o cenário carioca e apontam possíveis caminhos para os estudos urbanos. O olhar socioantropológico deve buscar alcançar os escapes do cotidiano 
encenados na obra analisada, assim como deve explorar os territórios conhecidos como subúrbios, periferias e favelas que são complexamente descritos nessa ficção.

\section{Referências}

CERTEAU, Michel de. A invenção do cotidiano: artes de fazer. Petrópolis: Editora Vozes, 1998.

CALDEIRA, Teresa Pires do Rio. Cidades de muros: crimes, segregação e cidadania em São Paulo. São Paulo: Editora 34, 2011.

GOFFMAN, Erving. Estigma: notas sobre a manipulação da identidade deteriorada. LTC: Rio de Janeiro, 2004.

GORTÁZAR, Naira Galarraga. Geovani Martins: "Percebi que era negro na FLIP, porque era o único". El País, Rio de Janeiro, 06 de set. de 2019. Disponível em: https://brasil.elpais.com/brasil/2019/09/16/cultura/1568657421_834925.html. Acesso em: 10 ago. 2021.

INSTITUTO DE SEGURANÇA PÚBLICA. Unidade de Polícia Pacificadora. Disponível em: http://www.ispdados.rj.gov.br/UPP.html. Acesso em: 10 ago. 2021.

LEITE, Rogério Proença. A Inversão do Cotidiano: Práticas Sociais e Rupturas na Vida Urbana Contemporânea. DADOS - Revista de Ciências Sociais, Rio de Janeiro, vol. 53, no 3, 2010: 737 a 756.

MAGNANI, José Guilherme Cantor. DE PERTO E DE DENTRO: notas para uma etnografia urbana. Revista Brasileira de Ciências Sociais, vol. 17, n. 49, 2002.

MARTINS, Geovani. O Sol na Cabeça. São Paulo: Companhia das Letras, 2018.

O’DONNELL, Julia. No olho da rua: a cidade de João do Rio. Dissertação (Mestrado em Antropologia Social) - Museu Nacional, Universidade Federal do Rio de Janeiro, 2007.

PARK, Robert E. A Cidade: sugestões para a investigação do comportamento humano no meio urbano. In: VELHO, Otavio (org.). O fenômeno urbano. Rio de Janeiro: Zahar, 1979.

SIMMEL, Georg. As grandes cidades e a vida do espírito. Mana, Rio de Janeiro, vol. 11, n. 2, 2005.

TORRES, Bolívar. Quem é o jovem Geovani Martins, a nova aposta da literatura nacional. $O$ Globo, Rio de Janeiro, 02 de mar. de 2018. Disponível em: https://oglobo.globo.com/cultura/livros/quem-o-jovem-geovani-martins-nova-aposta-daliteratura-nacional-22448355. Acesso em: 10 ago. 2021. 
VELHO, Gilberto. Um antropólogo na cidade: ensaios de antropologia urbana. Rio de Janeiro: Zahar, 2013.

Data de submissão: 30 de agosto de 2021

Data de publicação: 20 de dezembro de 2021 